\title{
Alien ectomycorrhizal plants differ in their ability to interact with co- introduced and native ectomycorrhizal fungi in novel sites
}

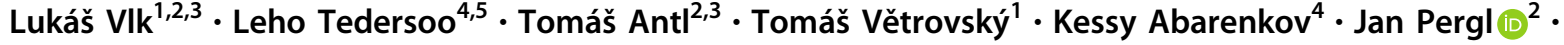 \\ Jana Albrechtová ${ }^{3} \cdot$ Miroslav Vosátka ${ }^{2,3} \cdot$ Petr Baldrian $\mathbb{1}^{1} \cdot$ Petr Pyšek ${ }^{2,3,6} \cdot$ Petr Kohout $\mathbb{D}^{1,2,3}$
}

Received: 20 November 2019 / Revised: 7 May 2020 / Accepted: 27 May 2020 / Published online: 4 June 2020

(c) The Author(s), under exclusive licence to International Society for Microbial Ecology 2020

\begin{abstract}
Alien plants represent a potential threat to environment and society. Understanding the process of alien plants naturalization is therefore of primary importance. In alien plants, successful establishment can be constrained by the absence of suitable fungal partners. Here, we used 42 independent datasets of ectomycorrhizal fungal (EcMF) communities associated with alien Pinaceae and Eucalyptus spp., as the most commonly introduced tree species worldwide, to explore the strategies these plant groups utilize to establish symbioses with EcMF in the areas of introduction. We have also determined the differences in composition of EcMF communities associated with alien ectomycorrhizal plants in different regions. While alien Pinaceae introduced to new regions rely upon association with co-introduced EcMF, alien Eucalyptus often form novel interactions with EcMF species native to the region where the plant was introduced. The region of origin primarily determines species composition of EcMF communities associated with alien Pinaceae in new areas, which may largely affect invasion potential of the alien plants. Our study shows that alien ectomycorrhizal plants largely differ in their ability to interact with cointroduced and native ectomycorrhizal fungi in sites of introduction, which may potentially affect their invasive potential.
\end{abstract}

\section{Introduction}

Introductions of alien species into new areas may strongly affect the structure and functioning of ecosystems and

Supplementary information The online version of this article (https:// doi.org/10.1038/s41396-020-0692-5) contains supplementary material, which is available to authorized users.

Petr Kohout

petr.kohout@natur.cuni.cz

1 Institute of Microbiology of the Czech Academy of Sciences, Vídeňská 1083, CZ-142 20 Prague, Czech Republic

2 Institute of Botany of the Czech Academy of Sciences, Zámek 1, CZ-252 43 Průhonice, Czech Republic

3 Faculty of Science, Charles University, Viničná 7, CZ-128 44 Prague, Czech Republic

4 Natural History Museum, University of Tartu, 14a Ravila, 50411 Tartu, Estonia

5 Department of Biology, King Saud University, Riyadh 11451, Saudi Arabia

6 Department of Botany and Zoology, Stellenbosch University, Matieland 7602, South Africa communities of native organisms [1-3]. Human migrations and global trade have tremendously increased introductions of non-native species to novel regions [4], causing huge economic costs worldwide [5, 6]. Success of alien species establishing in new areas is determined by numerous factors, such as the pathway of introduction, amount of propagules introduced to a site, climate match between the native and invaded range, probability of encountering suitable habitats, and species traits that manifest in biotic interactions [7-10]. Beyond their native distribution range, alien species can benefit from the escape from pathogens, predators, or competitors as predicted by the enemy release hypothesis [11]. By contrast, alien species' establishment in new environments can be constrained by the absence of suitable mutualists [7, 12]. Recent studies indicate that the role of mutualistic interactions is as important for the establishment of alien species as the escape from the effects of more commonly studied enemies, such as herbivores or pathogens [13-16].

The role of mutualistic interactions may be particularly important for introductions of plants with obligate symbiosis. Woody plants forming ectomycorrhizal (EcM) symbiosis with soil fungi represent an example of plants which cannot complete their life cycle without the 
mycobionts [12]. EcM fungi (EcMF) provide plants with mineral nutrients, water, or defense against pathogens, whereas plants supply EcMF with energy-rich carbon compounds in return [17]. To establish in plantations or successfully naturalize in new areas, EcM plants may either: (i) interact with EcMF co-introduced from the plant's native range (co-introduction), (ii) associate with EcMF, which naturally occur in both native and introduced range of the host plant (familiar association), or (iii) form novel associations with EcMF species native to the region where the plant was introduced (novel association) [18, 19].

Co-introductions of alien EcMF species together with their alien host trees were documented for introductions of pines (Pinaceae family) to the Southern Hemisphere [20]. Various EcMF were also co-introduced around the world with other plant groups, such as Alnus spp. or Coccoloba spp. [21-23]. Although Eucalyptus spp. were shown to be able to establish in new areas with the aid of novel associations with local EcMF [24], many EcMF were also cointroduced with eucalypts to new areas (e.g., [22, 25]). Therefore it is nowadays widely assumed, that cointroductions of EcMF represent the prevailing strategy of alien EcM plants to successfully establish in new areas [12].

In their native range, EcM plants usually host highly diverse EcMF communities on their root system [26, 27]. However, introductions to the new areas often lead to substantial reduction of EcMF species richness, with an extreme example of a single co-introduced EcMF species on roots of successfully established seedlings of Pinus contorta [28]. It remains questionable whether the successful introductions of EcM plants, other than pines, can also be associated with a few distinctive EcMF species [29] or rather associated with broad spectra of EcMF species. This might have important consequences for management of EcM plant and fungal invasions [30].

Understanding of the process of EcM plant naturalization in new areas is an issue of primary importance, because EcM plants form a disproportionately high share of alien trees globally, and many of them are regarded as the most severe invaders [31-34]. Although the global share of EcM plants is estimated between 1.7 and $2.4 \%$ of higher plant species [35], 21\% of the 90 most hazardous alien plants are EcM [36]. The majority of introduced EcM plants belong to the families Pinaceae (represented particularly by pines) and Myrtaceae (represented by eucalypts), due to their massive planting in the last century [37, 38], commonly in areas with native vegetation of mostly different mycorrhizal type [14, 39]. Members of Pinaceae and Myrtaceae also belong to the 90 most hazardous alien plants, namely: Pinus patula, $P$. pinaster, and $P$. radiata, Eucalyptus camaldulensis and E. globulus [36]. In many regions these introductions resulted in invasive spreading of the alien trees [40]. Pine invasions are recognized as important ecological phenomenon and threat to local diversity, especially in the Southern Hemisphere [41]. The importance of the their EcM mycobionts in the invasion dynamics is nowadays widely recognized $[16,28]$. Compared with Pinaceae, less species of Eucalyptus have become invasive [32, 42], but these numbers are likely to grow in the future [38, 43].

This paper aims to determine the share of mycorrhizal strategies (co-introduction vs. familiar association vs. novel association) among EcMF associated with alien Pinaceae and Eucalyptus on a global scale. These two groups were selected because they represent the most frequently introduced and cultivated woody plants worldwide $[31,44]$ and in numerous cases became invasive with detrimental effect on native ecosystems $[37,45,46]$. Particularly we aimed to find out if the share of mycorrhizal strategies differs between the two groups of alien plants or among geographical regions to which the alien plants were introduced. In addition, we sought to determine differences in composition of EcMF communities associated with alien EcM plants in different regions to which they were introduced. These objectives were achieved by using a metastudy and synthesis approach based on fungal sequences deposited in public databases and our own unpublished results.

\section{Materials and methods}

\section{Data sources}

This global-scale data synthesis is based on data from individual studies that focused on molecular identification of EcMF communities associated with alien plants sampled from habitats in their introduced range. The list of studies was compiled from the Web of Science and Google Scholar (5 November 2018) by searching for combination of terms 'non-native', 'alien*', 'invasion*' and 'introduction*' with 'ectomycorrhiza*', yielding over 200 results. The final selection included studies in which at least one alien EcM plant species belonged to Pinaceae (e.g., Pinus spp., Abies spp., Pseudotsuga spp.) or Myrtaceae (Eucalyptus spp.) and where root-associated EcMF were identified using sequencing of the ITS region of rDNA. The ITS region was chosen, because it represents the most commonly used barcoding region for fungi [47]. Studies with experimentally manipulated soil treatments were excluded. Besides that, we also searched for sequences of EcM mycobionts associated with alien EcM plants in public sequence repositories, such as UNITE [48] or INSDC (International Nucleotide Sequence Database Collaboration; http://www. insdc.org). The final dataset (17 published studies) was complemented with our unpublished data, which met the criteria listed above. Altogether our study was based on 42 independent datasets (Table 1; Supplementary Table S1). 
Table 1 List of datasets of EcMF associated with exotic Pinaceae and Eucalyptus spp. trees, included in this study.

\begin{tabular}{|c|c|c|c|c|c|}
\hline $\mathrm{ID}^{\mathrm{a}}$ & Country & Region & Host plant & GPS coordinates & Reference $^{\mathrm{b}}$ \\
\hline 1 & Iran & Eurasia & Pinus sylvestris & $36.0666667 \mathrm{~N}, 53.1500000 \mathrm{E}$ & Bahram et al. [26] \\
\hline 2 & Argentina & South America & Pinus ponderosa & 43.170055S, 71.509176W & Barroetaveña et al. 2010 \\
\hline 3 & Pakistan & Eurasia & Eucalyptus sp. & $31.3333 \mathrm{~N}, 74.0833 \mathrm{E}$ & Bashir et al. [97] \\
\hline 4 & Spain & Eurasia & Eucalyptus globulus & $42.333333 \mathrm{~N}, 8.550000 \mathrm{~W}$ & Calviño-Cancela (unpublished) \\
\hline 5 & Spain & Eurasia & Eucalyptus globulus & $42.233333 \mathrm{~N}, 8.350000 \mathrm{~W}$ & Calviño-Cancela (unpublished) \\
\hline 6 & Spain & Eurasia & Eucalyptus globulus & $42.283053 \mathrm{~N}, 8.767100 \mathrm{~W}$ & Calviño-Cancela (unpublished) \\
\hline 7 & New Zealand & Oceania & Pinus contorta & Not available & Dickie and Bolstridge (unpublished) \\
\hline 8 & South Africa & Africa & Pinus patula & $24.590507 \mathrm{~S}, 30.190191 \mathrm{E}$ & Hawley et al. [74] \\
\hline 9 & Argentina & South America & Pinaceae & $40.983546 \mathrm{~S}, 71.513335 \mathrm{~W}$ & Hayward et al. [28] \\
\hline 10 & Argentina & South America & Pinus sp. & 40.983546S, 71.513335W & Hayward et al. [28] \\
\hline 11 & Argentina & South America & Pseudotsuga sp. & $40.983546 \mathrm{~S}, 71.513335 \mathrm{~W}$ & Hayward et al. [28] \\
\hline 12 & Chile & South America & Pinus contorta & $45.500556 \mathrm{~S}, 71.704167 \mathrm{~W}$ & Hayward et al. [76] \\
\hline 13 & Japan & Eurasia & Pinus strobus & $36.104166 \mathrm{~N}, 138.233841 \mathrm{E}$ & Hirose (unpublished) \\
\hline 14 & Hawaii & Oceania & Pinus sp. & $20.769167 \mathrm{~N}, 156.241111 \mathrm{~W}$ & Hynson et al. [73] \\
\hline 15 & Kenya & Africa & Eucalyptus sp. & $0.17073 S, 35.59617 \mathrm{E}$ & Kluthe et al. 2016 \\
\hline 16 & Czech Republic & Eurasia & Pinus strobus & $50.870000 \mathrm{~N}, 14.381667 \mathrm{E}$ & Kohout et al. [82] \\
\hline 17 & China & Eurasia & Pinus elliottii & $28.102491 \mathrm{~N}, 113.034989 \mathrm{E}$ & Ning (unpublished) \\
\hline 18 & Argentina & South America & Pseudotsuga menziesii & $40.950415 \mathrm{~S}, 71.537314 \mathrm{~W}$ & Nuñez et al. [13] \\
\hline 19 & Argentina & South America & Pinus ponderosa & $40.983546 \mathrm{~S}, 71.513335 \mathrm{~W}$ & Nuñez et al. [75] \\
\hline 20 & Argentina & South America & Pseudotsuga menziesii & $40.983546 \mathrm{~S}, 71.513335 \mathrm{~W}$ & Nuñez et al. [75] \\
\hline 21 & Ireland & Eurasia & Picea sitchensis & $52.883333 \mathrm{~N}, 7.366667 \mathrm{~W}$ & O’Hanlon et al. 2012 \\
\hline 22 & China & Eurasia & Eucalyptus grandis & Not available & Pan et al. (unpublished) \\
\hline 23 & UK & Eurasia & Eucalyptus nitens & $51.479800 \mathrm{~N}, 0.2965000 \mathrm{~W}$ & Pennington et al. [94] \\
\hline 24 & UK & Eurasia & Eucalyptus gunnii & $51.479800 \mathrm{~N}, 0.296500 \mathrm{~W}$ & Pennington et al. [94] \\
\hline 25 & Poland & Eurasia & Abies alba & $54.2152 \mathrm{~N}, 17.9860 \mathrm{E}$ & Rudawska et al. 2016 \\
\hline 26 & Reunion & Africa & Eucalyptus camaldulensis & Not available & Sené et al. (unpublished) \\
\hline 27 & Senegal & Africa & Eucalyptus camaldulensis & Not available & Sené et al. (unpublished) \\
\hline 28 & Seychelles & Africa & Eucalyptus sp. & 4.623930S, 55.433089E & Tedersoo et al. [24] \\
\hline 29 & Seychelles & Africa & Pinus caribaea & 4.623930S, 55.433089E & Tedersoo et al. [24] \\
\hline 30 & Madagascar & Africa & Eucalyptus sp. & 24.966711S, 46.99986E & Tedersoo et al. [24] \\
\hline 31 & Zambia & Africa & Eucalyptus camaldulensis & $13.316667 \mathrm{~S}, 24.500000 \mathrm{E}$ & Tedersoo et al. [77] \\
\hline 32 & Cameroon & Africa & Eucalyptus grandis & $5.016667 \mathrm{~S}, 8.800000 \mathrm{E}$ & Tedersoo et al. [77] \\
\hline 33 & Zambia & Africa & Eucalyptus grandis & $13.316667 \mathrm{~S}, 24.500000 \mathrm{E}$ & Tedersoo et al. [77] \\
\hline 34 & Madagascar & Africa & Eucalyptus robusta & $24.966711 \mathrm{~S}, 46.99986 \mathrm{E}$ & Tedersoo et al. [77] \\
\hline 35 & Zambia & Africa & Pinus kesiya & $13.316667 \mathrm{~S}, 24.500000 \mathrm{E}$ & Tedersoo et al. [77] \\
\hline 36 & Cameroon & Africa & Pinus sp. & $5.016667 \mathrm{~S}, 8.800000 \mathrm{E}$ & Tedersoo et al. [77] \\
\hline 37 & New Zealand & Oceania & Pinus radiata & $44.245800 \mathrm{~S}, 176.24000 \mathrm{~W}$ & Walbert et al. [77] \\
\hline 38 & Czech Republic & Eurasia & Pinus strobus & $50.870000 \mathrm{~N}, 14.430000 \mathrm{E}$ & This study \\
\hline 39 & Madeira & Africa & Cedrus deodara & Not available & This study \\
\hline 40 & Madeira & Africa & Eucalyptus globulus & Not available & This study \\
\hline 41 & Madeira & Africa & Pinus pinaster & Not available & This study \\
\hline 42 & Estonia & Eurasia & Abies sachalinensis & $58.686316 \mathrm{~N}, 26.582143 \mathrm{E}$ & This study \\
\hline
\end{tabular}

Where available, we provide GPS information obtained from the original publications or public databases.

${ }^{a}$ ID numbers are used as identificators of individual datasets in Figs. 1 and 2.

${ }^{\mathrm{b}}$ Full references are provided in Supplementary Table 2.

For each dataset, metadata on geographic (latitude, longitude), host plant species and environmental variables were retrieved from the original publications or public databases, if available. 
Morphotyping of EcM root tips with subsequent Sanger sequencing of the ITS rDNA region was applied for mycobiont identification in all of the analysed studies as high-throughput sequencing (HTS) studies on this topic were unavailable. All sequences from the selected studies were downloaded in FASTA format from INSD or obtained directly from the individual studies, in cases where the sequences were provided in supplementary materials. The obtained sequences were individually checked and only those without ambiguous bases and covering full length of at least one of the variable regions of the ITS were used for subsequent analysis. These sequences were then assigned to existing units corresponding to fungal Species Hypothesis [49] (referred to as SH from here on) based on BLASTn [50] search on $98.5 \%$ sequence similarity level. Detected SHs were assigned to existing EcM lineages based on previous studies [51, 52]. Non-EcM SHs were excluded from analysis.

To determine putative native ranges of EcM fungal SHs, we used (i) SH's distribution maps implemented in UNITE [49] (19 November 2018), after excluding all sequences associated with non-native EcM vegetation and (ii) a newly developed database of fungal HTS studies [53]. Only studies reporting fungal community composition in natural vegetation without any non-native EcM plants were included in the HTS database. Combining these two independent sources enabled us to determine the putative native ranges of EcMF SHs from Sanger sequencing as well as HTSbased studies, yielding probably the most comprehensive overview of global distribution of EcMF so far.

Based on putative native distributions of the $\mathrm{SHs}$, we assigned them to three biogeographic categories. The assignment was done independently for each dataset. The three biogeographic categories were based on the simplified framework of Dickie et al. [18, 19]. This framework is so far the only one which conceptualized plant-fungal invasions from the perspective of plant and fungal origin. Specifically, we assigned all EcMF SHs to: (i) co-introduction: introduction to a new region of an alien $\mathrm{SH}$ with an alien plant, either concurrently or asynchronously, (ii) familiar association: an alien plant associates with an $\mathrm{SH}$ native to the plant's both native and novel ranges, and (iii) novel association: interaction between alien plant and $\mathrm{SH}$ native to the plant's new range. The biogeographic categories were not defined for SHs with a low number of records in UNITE or HTS database (less than five records) as previously described in Vlk et al. [54]. Biogeographical regions were determined according to Morrone [55].

\section{Statistical analyses}

To determine the differences in community composition of EcMF associated with alien trees among biogeographic regions, we performed permutational ANOVA (PERMANOVA) as implemented in the adonis function of the VEGAN package in $\mathrm{R}$ [56]. First, we transformed all datasets into binary format, because many datasets did not provide quantitative information about EcM morphotypes or species. The Sørensen dissimilarity metric was then used to calculate the distance matrix of the EcMF communities. To assess whether differences in fungal communities among biogeographic regions were statistically significant, 999 permutations were used. Adjusted $R^{2}$ were calculated based on the Adonis results in order to check for model quality. Pairwise PERMANOVA with 99,999 permutations was performed to test differences in composition of EcMF communities between geographical regions. Bonferroni correction was used to calculate the corrected $P$ value determined by the pairwise PERMANOVA analysis. The Sørensen dissimilarity of the EcMF communities was used for nonmetric multidimensional scaling (NMDS) analyses in the ECODIST package [57]. Only samples with sufficient species overlap were included in the NMDS analysis. We also analyzed the response of EcMF composition variation to biogeographic regions. Composition variation was defined following [58] as variation $\beta$-diversity, which is the variance calculated for the different samples per a biogeographic region. For statistical comparison, the composition variation was calculated using the functions betadisper and permutest.betadisper in the VEGAN package of R software.

To test whether there are differences in the strategies that alien EcM plants adopt to establish in the new areas among geographic regions, their counts were analysed by row $\times$ column contingency tables, using generalized linear models with the log-link function and a Poisson distribution of errors [59]. For the models that significantly explained the effects, adjusted standardized residuals of $G$-tests were then compared with critical values of the normal distribution to ascertain for which species groups the counts are lower or higher than expected by chance [60]; see e.g., [61]. To test whether alien Pinaceae and Eucalyptus adopt different strategies to associate with suitable EcMF in the new areas, nonparametric Mann-Whitney-Wilcoxon test was applied. All calculations were done in R 3.5.0 software [62].

\section{Results}

\section{Description of the dataset}

Our data synthesis is based on 42 independent datasets (28 published and 14 unpublished) of EcMF communities associated with alien woody plants worldwide. Most datasets were obtained from Africa (16), Europe (10), South America (8), Oceania (3), and Asia (5). EcM fungal communities associated with alien Pinaceae (e.g., Abies alba, 
Pinus strobus, P. contorta, P. elliottii, Pseudotsuga menziesii) and the genus Eucalyptus were represented by 25 and 17 datasets, respectively.

In total, 1167 fungal ITS sequences were obtained from roots of alien EcM plants (ranging from 1 to 77 sequences per dataset). After filtering steps, 401 sequences were retained and further assigned to 273 fungal SHs (based on 98.5\% sequence similarity thresholds) with EcM lifestyle. Natural distribution area was determined based on our criteria for almost $270 \mathrm{SHs}$ and these SHs were subsequently assigned to one of the three biogeographic categories (number of records per category: 209 co-introductions; 100 native to both areas; 76 novel interactions) in each dataset separately (Supplementary Table S2). Overall, alien Eucalyptus spp. tended to enter novel association (in 11 of 17 studies) with native EcMF in new areas more often than alien Pinaceae spp. (in 10 of 25 studies; Mann-WhitneyWilcoxon test; $p=0.021$ ). Association with familiar or cointroduced EcMF did not differ between the two groups of alien plants.

\section{EcMF associated with alien Pinaceae species}

EcMF associated with alien plant species from the Pinaceae family were represented by 25 datasets (South America-8, Eurasia-8, Africa-6, and Oceania-3). Tomentella, Suillus, and Russula were the most species-rich EcM fungal genera associated alien Pinaceae species, represented by 22, 20, and $15 \mathrm{SHs}$, respectively. The share of strategies that Pinaceae species adopted to establish EcM partnership in new regions differed profoundly among biogeographic regions (Fig. 1a). While alien Pinaceae almost exclusively associated with co-introduced EcMF in regions with no native Pinaceae spp. (such as South America, Africa, and Oceania), familiar or novel associations with native EcMF prevailed among alien Pinaceae introduced to regions where other members of the Pinaceae family naturally occur (Table 2). Although co-introduced EcMF dominated on roots of the Pinaceae species in the Southern Hemisphere (mostly Argentina), the alien plants were in some cases $(\sim 25 \%)$ also able to form novel interactions with native EcMF, such as Ruhlandiella sp. (SH207800.07FU), Sebacina sp. (SH214642.07FU), or Thelephoraceae sp. (SH010118.07FU). Only nine EcMF species associated with alien Pinaceae trees in regions where other members of the Pinaceae family naturally occur can be considered as putative alien species (Supplementary Table S2).

The composition of EcMF communities associated with alien Pinaceae showed distinct patterns among geographic regions. Alien Pinaceae species tend to associate with distinct EcMF communities in regions with and without native Pinaceae spp. (PERMANOVA, $n=21$; df $=1 ; F=1.93 ; p<$ $\left.0.01 ; R^{2}=0.1\right)$. While in the regions without native Pinaceae spp., EcMF communities associated with Pinaceae trees were dominated by Hebeloma mesophaeum (SH218845.07FU), Suillus pseudobrevipes (SH176742.07FU) and Thelephoraceae sp. 1 (SH189355.07FU), Cenococcum geophilum (SH214459.07FU) and Tylospora sp. (SH192265.07FU) were commonly found on roots of alien Pinaceae species in the regions with native Pinaceae spp. (Fig. 2). Interestingly, the composition of EcMF communities also differed among the regions without native Pinaceae spp. (PERMANOVA, $n=$ 13 ; df $\left.=2 ; F=1.96 ; p<0.01 ; R^{2}=0.28\right)$. While EcMF community composition did not differ between alien Pinaceae in South America and Oceania, it differed between alien Pinaceae from these two regions and Africa (Fig. 2).

EcM fungal communities associated with alien Pinaceae also differed in composition overlap between the regions with and without native Pinaceae spp. While only $13 \%$ of SHs were detected in at least two samples in the regions with native Pinaceae spp., 63\% of SHs were shared among two or more sites in the regions without native Pinaceae spp.

\section{EcMF associated with alien Eucalyptus species}

EcMF associated with alien eucalypts were represented by 17 datasets (Africa-10 and Eurasia-7). Predominantly cointroduced EcMF and novel associations with local EcMF were recorded while familiar associations were almost absent (Fig. 1b). Laccaria, Clavulina, and Tomentella were the most species-rich EcM fungal genera associated with alien Eucalyptus species. All reported datasets were obtained in regions without natural distribution of Eucalyptus spp. or any other EcM members of the Myrtaceae family.

Species composition of EcMF communities associated with alien eucalypts showed very little overlap among the datasets (for more details see Supplementary Table S3). More than $80 \%$ of all EcMF associated with alien eucalypts were recorded only once. Therefore, we were not able to statistically analyse differences in the composition of eucalypt-associated EcMF communities among regions. Scleroderma albidum (SH179810.07FU) and Scleroderma sp. (SH179808.07FU) were the most frequently detected EcMF associated with alien eucalypts. These two putatively co-introduced EcMF species were both recorded in five datasets.

\section{Discussion}

EcM plant species form a disproportionately high share of alien trees globally, and many of them are regarded as the most severe invaders [31-34]. Recently, Moyano et al. [63] provided evidence that alien EcM plants that rely more on EcMF are more prone to become invasive in introduced 

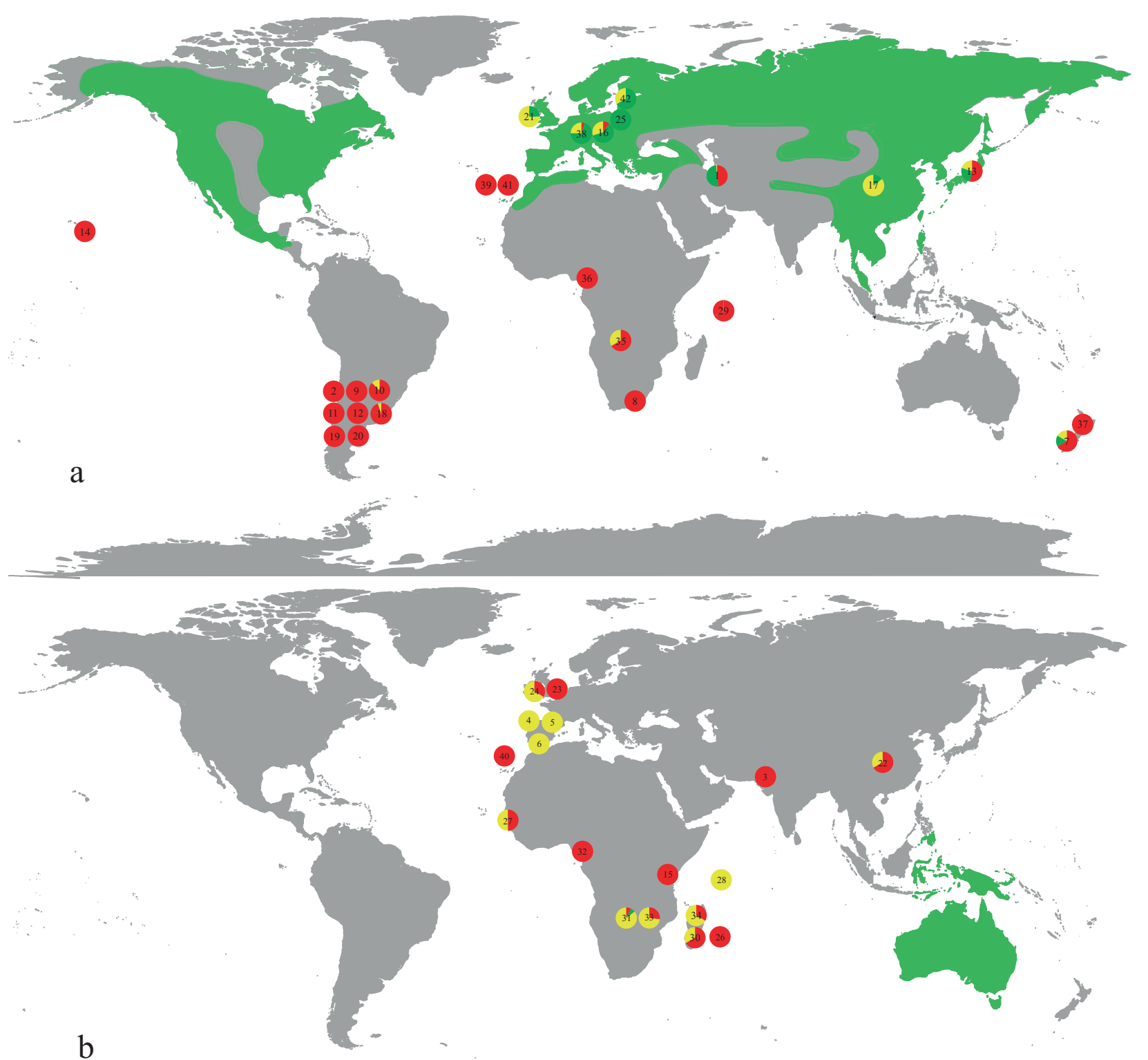

b

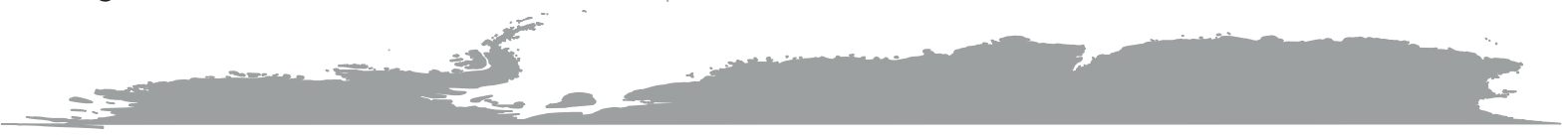

Fig. 1 Global distribution of analysed datasets of EcMF communities associated with alien Pinaceae and alien eucalypts. Global distribution of analysed datasets of EcMF communities (pie charts) associated with (a) alien Pinaceae and (b) alien eucalypts. Colors of the pie charts indicate share of the three strategies that alien EcM plants adapted to establish in new areas: interaction with co-introduced EcMF from their native range (red), association with EcMF which

regions. Therefore, our study, which provides the most comprehensive overview of strategies that alien EcM plants adopted to establish a mycorrhizal partnership in regions to which they were introduced, represents a substantial step forward in understanding the mechanisms of EcM plant naturalization. The 42 analysed datasets of EcMF communities associated with alien EcM plants concern species of naturally occur in both native as well as introduced regions of the host plant (green), and establishment of novel associations with native EcMF species (yellow; based on Dickie et al. [18] and Dickie et al. [19]). Native distribution ranges of Pinaceae and eucalypts are highlighted by green color based on Stevens et al. [99]. Numbers in the pie charts correspond to the ID of individual EcMF datasets (Table 1).

the Pinaceae family and Eucalyptus. Yet, our study is of general interest not only due to its nearly global coverage, but also because these two groups represent the most widely introduced EcM plants worldwide [31, 44] including many highly invasive species [64].

The lack of mutualists represents one of the main hypotheses explaining failure of introduced tree species 
Table 2 Distribution of strategies that alien Pinaceae adopt to associate with suitable EcMF in regions with no native Pinaceae spp.

\begin{tabular}{lll}
\hline EcM strategy & $\begin{array}{l}\text { Regions without } \\
\text { native Pinaceae }\end{array}$ & $\begin{array}{l}\text { Regions with native } \\
\text { Pinaceae }\end{array}$ \\
\hline Co-introduction & $125^{+}$ & $44^{-}$ \\
Native to both areas & $1^{-}$ & $98^{+}$ \\
Novel interaction & 4 & 24 \\
\hline
\end{tabular}

Strategies that are significantly over- or under- represented in regions with or without native Pinaceae species compare with the proportion expected by chance $(G$-test, $p$ value $<0.001)$ are marked by + indicating over- or under- representation within the group.

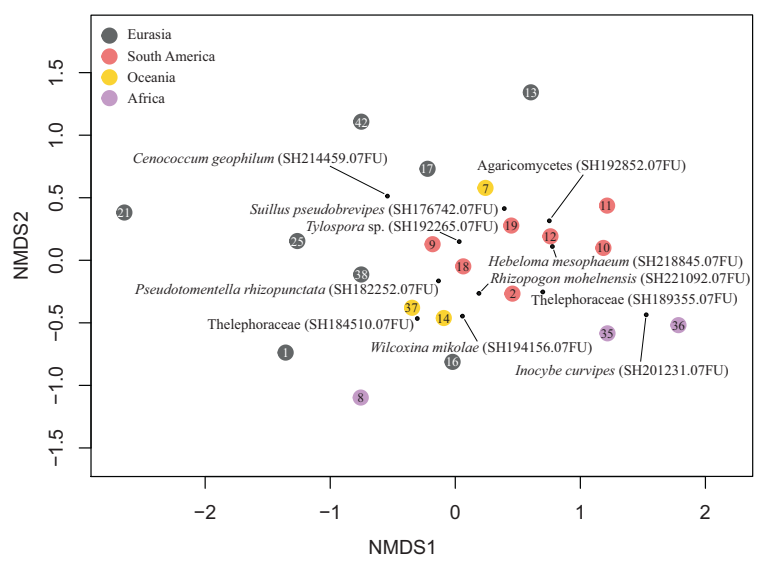

Fig. 2 Nonmetric multidimensional scaling (NMDS) plot of community composition of EcMF associated with alien Pinaceae. Symbols with numbers correspond to the individual datasets. Colors of the symbols indicate different geographical regions of origin. Black dots indicate positions of the most common EcMF in the ordination space. Stress value $=0.21$. Numbers in the sample points correspond to the ID of individual EcMF datasets (Table 1).

$[65,66]$. To overcome the barrier of obligatory symbiotic lifestyle, alien EcM plants are believed to rely on association with co-introduced EcMF from their native distribution range [15]. Although this mechanism was suggested by studies on alien EcM plant species from various regions (e.g., $[12,18,21,22])$, we provide the first comprehensive test of this hypothesis on a global scale. We found that the occurrence of co-introduced EcMF on roots of alien EcM plants as well as their ability to form novel interactions with native EcMF differed among biogeographical regions as well as between the two studied plant groups. While Pinaceae introduced to sites without other native Pinaceae spp. relied upon interaction with co-introduced EcMF, native EcMF dominated on roots of alien Pinaceae on sites where other Pinaceae spp. naturally occur. Compared with the alien Pinaceae, the alien Eucalyptus spp. more often formed novel associations with native EcMF on sites of introduction. These observed patterns can be potentially explained by different level of specificity of EcMF communities of Pinaceae spp. (gymnosperms) and Eucalyptus spp. (angiosperms). While some
Pinaceae species are known to evince certain level of specificity by interacting with specific groups of EcMF [67-69], Eucalyptus spp. usually associate with more generalist EcMF communities [70]. Although previous case studies indicated that plant hosts with specialized and generalized EcMF communities rely upon association with co-introduced EcMF [21, 24], our global comparison of alien Pinaceae and Eucalyptus may indicate distinct pattern. However, to generalize our conclusions to all alien EcM plants, more data are needed particularly for alien EcM plants from other angiosperm families.

Although our study represents so far the most comprehensive comparison of EcMF associated with alien woody plants on a large spatial scale, many geographical regions are still largely undersampled. Numerous European Pinaceae spp. [71] as well as other EcM plants [40, 72] have been historically planted in North America. Similarly, Eucalyptus spp. were introduced to South America [25, 34], where they often spread into native vegetation [38]. Unfortunately, we lack information about EcMF communities associating with the above-mentioned alien plants from these regions. Similarly, more studies reporting EcMF communities from native vegetation from various biogeographical regions will largely increase precision of the native ranges of EcMF species.

\section{EcMF associated with alien Pinaceae}

Co-introduced EcMF dominated on alien Pinaceae roots in case the host plants were introduced into areas without any native Pinaceae species (e.g., Africa, Oceania and South America). Not surprisingly, this pattern was strongest in regions with no native EcM vegetation, such as Madeira (this study) and Hawaii [73] islands or South African fynbos vegetation [74]. Co-introduced EcMF also prevailed on roots of alien Pinaceae when the host plants were introduced to areas with native EcM vegetation formed by other than Pinaceae species. These cases were represented by introductions of Pinaceae spp. to Patagonia where natural vegetation is dominated by EcM Nothofagus spp. (e.g., $[75,76])$, to Zambia, where large areas are still covered with EcM miombo forests [77] or to New Zealand with several native EcM tree species (e.g., [78]). Therefore, our study, in accordance with previous works (e.g., [12, 18]), shows comprehensive evidence that Pinaceae introduced to regions without naturally occurring Pinaceae associate almost exclusively with co-introduced EcMF.

EcMF communities associated with alien Pinaceae introduced to sites with and without native Pinaceae species showed only a limited overlap. Although these results are based on relatively small number of samples, we identified similarities among EcMF communities from South America and Oceania with only limited overlap with communities in 
Africa. This pattern may be explained by differences in biogeographical origins of the alien Pinaceae species introduced to these regions. While all studied alien Pinaceae in South America and Oceania originated from the west coast of North America (Pinus ponderosa, P. contorta, P. radiata, and Pseudotsuga menziesii), the analysed alien Pinaceae in Africa were introduced from Mexico ( $P$. patula) or Southeast Asia (P. kesiya). Therefore, we assume that the original distribution range represents the best predictor of EcMF communities associated with alien Pinaceae. Similar comigration patterns of host plant and mycorrhizal fungi were previously reported for postglacial expansion of Tuber melanosporum and oaks and hazelnuts [79], ancient migration patterns of Alnus spp. and associated EcMF [80] and comigration of Ericaceae spp. and their mycobionts from the Sebacilanes order [81].

Only very few co-introduced EcMF associated with alien Pinaceae on sites where other Pinaceae species naturally occur (e.g., Europe and Asia). In our dataset, Rhizopogon salebrosus represented the only known co-introduced EcMF species associated with roots of alien Pinaceae in Europe [82]. $R$. salebrosus was recently also found on roots of $P$. strobus and P. menziesii in Poland [83]. In case of introduction of North American P. elliottii into continental Asia, we did not find any associated co-introduced EcMF at all (Ning, unpublished). Clearly, alien species of Pinaceae introduced to the sites where other Pinaceae species naturally occur rather associated with native EcMF. Although the association between EcMF and certain Pinaceae spp. shows some specificity, the specificity at the plant species level is relatively low [67-69]. Therefore, the presence of distantly related plants from the Pinaceae family and their EcMF symbionts probably enables alien members of this family to enter novel associations in the regions of introduction. This observation corresponds to previously formulated hypothesis that phylogenetic distance between the alien plant and the native species in the community facilitates its integration into the community-phylogenetically closer aliens have to overcome weaker barriers to successful establishment $[84,85]$. Similarly, alien species with traits similar to native species are more likely to successfully naturalize than those that are different [86]. The only exception from this general pattern represents dataset from Japan. There, we identified several co-introductions of EcMF associated with North American P. strobus (Hirose, unpublished). We speculate that this discrepancy can be explained by island biogeography, because it is generally assumed that islands are more prone to introductions of alien species [87].

EcMF communities associated with alien Pinaceae on sites where other Pinaceae species naturally occur were characterized by presence of the globally distributed Cenococcum geophilum complex [88] and differed from EcMF communities associated with Pinaceae from sites without any native Pinaceae. The only exception represented EcMF community associated with alien Pinus strobus in Czechia [82]. In this particular case, EcMF community rather resembled those associated with Pinaceae introduced to sites without native Pinaceae vegetation. Importantly, the Czech dataset was obtained from a pot experiment, where seedlings of $P$. strobus were cultivated in forest soil from $P$. strobus dominated sites. Therefore, EcMF from soil spore bank dominated the $P$. strobus associated EcMF community developing in pot microcosms. The overlap of EcMF communities from the Southern Hemisphere with this particular dataset indicate that EcMF with stronger potential to regrowth from the soil spore bank prevail on roots of alien Pinaceae on sites without native Pinaceae species, as previously indicated [76].

Altogether, our study documented several factors which can influence the composition of EcMF communities associated with alien EcM plants on a large spatial scale. The information on the composition of EcMF communities associated with alien Pinaceae species is particularly important for prediction of the invasive potential of this important group of tree invaders. For example, Policelli et al. [16] recently indicated that one particular group of EcMF, the suilloid fungi, may trigger plant invasion. Besides that, composition of EcMF communities may largely affect ecosystem processes, such as carbon [89] or nutrient $[90,91]$ cycling.

\section{EcMF associated with alien Eucalyptus}

All studies focused on EcMF associated with alien Eucalyptus included in our metastudy were conducted in regions without native Eucalyptus spp. or any other EcM Myrtaceae. When introduced to regions with native vegetation dominated by EcM plant species, such as miombo forest vegetation in Zambia [92], Madagascar, and Seychelles with several native EcM plant families [93], or temperate EcM forests in UK [94], the alien eucalypts were able to establish EcM symbiosis with native mycobionts. These observations indicate an ability of eucalypts to enter novel associations in various vegetation types. Eucalypts from commercial plantations in Spain were observed to associate exclusively with native EcMF and never with co-introduced EcMF (Calviño-Cancela, unpublished). This contradicts previous reports of alien EcMF (Laccaria fraterna, Pisolithus albus, and P. microcarpus) originating from Australia and previously described from eucalypt plantations in Spain [22]. Such discrepancy between results based on fruiting body survey and analysis of EcMF community composition on host roots is well known [95]. We assume that in our case the missing co-introduced EcMF on roots of alien eucalypts can be explained by low sampling effort of the root-associated EcMF communities. However, it might also indicate that the association with native EcMF is more 
favorable for the establishment of the alien eucalypts than association with co-introduced mycobionts. The simultaneous association of eucalypts with both co-introduced and native EcMF was detected in several other datasets. It remains unknown how the association with co-introduced or native EcMF affects host plant physiology and establishment. The locally adapted native EcMF may be more mutualistic in the site-specific environmental conditions [96], while the co-introduced mycobionts may have more favorable effect on the host plants because of their long coevolutionary history. Relative role of the native and cointroduced EcMF in the establishment of alien EcM plants remains an open but important question for future research.

The EcMF communities associated with alien Eucalyptus spp. showed very low overlap in species composition among the analysed datasets. Basically, almost no fungal species was found twice on roots of Eucalyptus spp. in our final dataset. The only exceptions are co-introduced Scleroderma spp., which were detected on roots of alien eucalypts in several independent studies [77, 94, 97]. The low overlap of the EcMF communities indicates random selection of mycobionts by alien Eucalyptus spp. from local species pools, whose compositions may largely differ among biogeographical regions [98]. This observation can be again explained by ability of some Eucalyptus spp. to interact with more generalist EcMF communities compared with the alien Pinaceae [70]. We assume that establishment and potential spread of alien Eucalyptus is less constrained by the lack of compatible mutualistic fungi than in case of alien Pinaceae.

\section{Conclusions}

To conclude, alien EcM plants from the Pinaceae family and the genus Eucalyptus differ in the probability of finding suitable mycorrhizal partners in new areas. While alien Pinaceae introduced to new regions rely upon association with co-introduced EcMF, alien Eucalyptus often form novel interactions with EcMF species native to the region where the plant was introduced. The region of origin primarily determines species composition of EcMF communities associated with alien Pinaceae in a new area, which may largely affect invasion potential of the alien plants.

Acknowledgements The study was supported by the grant Biotic threats to monuments of garden art: algae, cyanobacteria, and invasive plants (DG16P02M041; NAKI II of the Ministry of Culture of the Czech Republic), and by Czech Science Foundation projects 1826191S and EXPRO 19-28807X.

\section{Compliance with ethical standards}

Conflict of interest The authors declare that they have no conflict of interest.
Publisher's note Springer Nature remains neutral with regard to jurisdictional claims in published maps and institutional affiliations.

\section{References}

1. Davis M. Invasion Biology, 1st ed. Oxford: Oxford University Press; 2009.

2. Vilà M, Bartomeus I, Dietzsch $\mathrm{AC}$, Petanidou $\mathrm{T}$, SteffanDewenter I, Stout JC, et al. Invasive plant integration into native plant-pollinator networks across Europe. Proc R Soc B Biol Sci. 2009;276:3887-93.

3. Blackburn TM, Essl F, Evans T, Hulme PE, Jeschke JM, Kühn I, et al. A unified classification of alien species based on the magnitude of their environmental impacts. PLoS Biol. 2014;12: e1001850.

4. Seebens H, Blackburn TM, Dyer EE, Genovesi P, Hulme PE, Jeschke JM, et al. No saturation in the accumulation of alien species worldwide. Nat Commun. 2017;8:1-9.

5. Vilà M, Basnou C, Pyšek P, Josefsson M, Genovesi P, Gollasch S, et al. How well do we understand the impacts of alien species on ecosystem services? A pan-European, cross-taxa assessment. Front Ecol Environ. 2010;8:135-44.

6. Bacher S, Blackburn TM, Essl F, Genovesi P, Heikkilä J, Jeschke JM, et al. Socio-economic impact classification of alien taxa (SEICAT). Methods Ecol Evol. 2018;9:159-68.

7. Richardson DM, Allsopp N, D'Antonio CM, Milton SJ, Rejmánek M. Plant invasions-the role of mutualism. Biol Rev. 2000;75:65-93.

8. Mitchell CE, Agrawal AA, Bever JD, Gilbert GS, Hufbauer RA, Klironomos JN, et al. Biotic interactions and plant invasions. Ecol Lett. 2006;9:726-40.

9. Catford JA, Smith AL, Wragg PD, Clark AT, Kosmala M, Cavender-Bares $\mathrm{J}$, et al. Traits linked with species invasiveness and community invasibility vary with time, stage and indicator of invasion in a long-term grassland experiment. Ecol Lett. 2019;22:593-604.

10. Pyšek P, Manceur AM, Alba C, McGregor KF, Pergl J, Štajerová $\mathrm{K}$, et al. Naturalization of central European plants in North America: Species traits, habitats, propagule pressure, residence time. Ecology. 2015;96:762-74.

11. Keane RM, Crawley MJ. Exotic plant invasions and the enemy release hypothesis. Trends Ecol Evol. 2002;17:164-70.

12. Nuñez MA, Dickie IA. Invasive belowground mutualists of woody plants. Biol Invasions. 2014;16:645-61.

13. Nuñez MA, Horton TR, Simberloff D. Lack of belowground mutualisms hinders Pinaceae invasions. Ecology. 2009;90:2352-5359.

14. Rundel PW, Dickie IA, Richardson DM. Tree invasions into treeless areas: mechanisms and ecosystem processes. Biol Invasions. 2014;16:663-75.

15. Delavaux CS, Weigelt P, Dawson W, Duchicela J, Essl F, van Kleunen M, et al. Mycorrhizal fungi influence global plant biogeography. Nat Ecol Evol. 2019;3:424-9.

16. Policelli N, Bruns TD, Vilgalys R, Nuñez MA. Suilloid fungi as global drivers of pine invasions. N. Phytol. 2019;222:714-25.

17. Smith SE, Read DJ. Mycorrhizal symbiosis. 3rd ed. New York, USA: Academic Press; 2008.

18. Dickie IA, Bolstridge N, Cooper JA, Peltzer DA. Co-invasion by Pinus and its mycorrhizal fungi. N. Phytol. 2010;187:475-84.

19. Dickie IA, Bufford JL, Cobb RC, Desprez-Loustau ML, Grelet G, Hulme PE, et al. The emerging science of linked plant-fungal invasions. N. Phytol. 2017;215:1314-32.

20. Marx DH. The practical significance of ectomycorrhizae in forest establishment. Ecophysiology of Ectomycorrhizae of Forest Trees. 
Stockholm, Sweden: Marcus Wallenberg Foundation; 1991. pp. 54-90.

21. Bogar LM, Dickie IA, Kennedy PG. Testing the co-invasion hypothesis: ectomycorrhizal fungal communities on Alnus glutinosa and Salix fragilis in New Zealand. Divers Distrib. 2015;21:268-78.

22. Díez J. Invasion biology of Australian ectomycorrhizal fungi introduced with eucalypt plantations into the Iberian Peninsula. Biol Invasions. 2005;7:3-15.

23. Séne S, Avril R, Chaintreuil C, Geoffroy A, Ndiaye C, Diédhiou $\mathrm{AG}$, et al. Ectomycorrhizal fungal communities of Coccoloba uvifera (L.) L. mature trees and seedlings in the neotropical coastal forests of Guadeloupe (Lesser Antilles). Mycorrhiza. 2015;25:547-59.

24. Tedersoo L, Suvi T, Beaver K, Kõljalg U. Ectomycorrhizal fungi of the Seychelles: diversity patterns and host shifts from the native Vateriopsis seychellarum (Dipterocarpaceae) and Intsia bijuga (Caesalpiniaceae) to the introduced Eucalyptus robusta (Myrtaceae), but not Pinus caribea (Pinaceae). N. Phytol. 2007;175:321-33.

25. Sulzbacher MA, Grebenc T, Bevilacqua CB, Steffen RB, Coelho $\mathrm{G}$, Silveira AO, et al. Co-invasion of ectomycorrhizal fungi in the Brazilian Pampa biome. Appl Soil Ecol. 2018;130:194-201.

26. Bahram M, Kõljalg U, Courty PE, Diédhiou AG, Kjøller R, Põlme $S$, et al. The distance decay of similarity in communities of ectomycorrhizal fungi in different ecosystems and scales. J Ecol. 2013;101:1335-44.

27. Thoen E, Aas AB, Vik U, Brysting AK, Skrede I, Carlsen T, et al. A single ectomycorrhizal plant root system includes a diverse and spatially structured fungal community. Mycorrhiza. 2019;29:167-80.

28. Hayward J, Horton TR, Pauchard A, Nuñez MA. A single ectomycorrhizal fungal species can enable a Pinus invasion. Ecology. 2015;96:1438-44.

29. Séne S, Selosse M-A, Forget M, Lambourdière J, Cissé K, Diédhiou AG, et al. A pantropically introduced tree is followed by specific ectomycorrhizal symbionts due to pseudo-vertical transmission. ISME J. 2018;12:1806-16.

30. Dickie IA, Nuñez MA, Pringle A, Lebel T, Tourtellot SG, Johnston PR. Towards management of invasive ectomycorrhizal fungi. Biol Invasions. 2016;18:3383-95.

31. Richardson DM. Forestry trees as invasive aliens. Conserv Biol. 1998;12:18-26.

32. Richardson DM, Pyšek P, Rejmánek M, Barbour MG, Panetta FD, West CJ. Naturalization and invasion of alien plants: concepts and definitions. Divers Distrib. 2000;6:93-107.

33. Richardson DM, Rejmánek M. Conifers as invasive aliens: a global survey and predictive framework. Divers Distrib. 2004;10:321-31.

34. Tedersoo L. Global biogeography and invasions of ectomycorrhizal plants: Past, present and future. Biogeography of Mycorrhizal Symbiosis. Springer International Publishing; Cham, Switzerland, 2017. pp 469-531.

35. Brundrett MC, Tedersoo L. Evolutionary history of mycorrhizal symbioses and global host plant diversity. N. Phytol. 2018;220:1108-15.

36. Traveset A, Richardson DM. Mutualistic interactions and biological invasions. Annu Rev Ecol Evol Syst. 2014;45:89-113.

37. Simberloff D, Nuñez MA, Ledgard NJ, Pauchard A, Richardson DM, Sarasola M, et al. Spread and impact of introduced conifers in South America: Lessons from other southern hemisphere regions. Austral Ecol. 2010;35:489-504.

38. Rejmánek M, Richardson DM. Eucalypts. In: Simberloff D, Rejmánek M, (eds). Encyclopedia of Biological Invasions. 1st ed. Berkeley and Los Angeles: University of California Press; 2011. p. 792.

39. Brundrett MC, Bougher NL, Dell B, Grove T, Malajczuk N. Working with mycorrhizas in forestry and agriculture. Canberra,
Australia: Australian Centre for International Agricultural Research; 1996.

40. Rejmánek M, Richardson DM. Trees and shrubs as invasive alien species-2013 update of the global database. Divers Distrib. 2013;19:1093-4.

41. Richardson DM, Williams PA, Hobbs RJ. Pine invasions in the Southern Hemisphere: determinants of spread and invadability. J Biogeogr. 1994;21:511-27.

42. Richardson DM, Hui C, Nuñez MA, Pauchard A. Tree invasions: patterns, processes, challenges and opportunities. Biol Invasions. 2014; $16: 473-81$.

43. Gordon DR, Flory SL, Cooper AL, Morris SK. Assessing the invasion risk of eucalyptus in the United States using the Australian weed risk assessment. Int J Res. 2012;2012:1-7.

44. Calviño-Cancela M, van Etten EJB. Invasive potential of Eucalyptus globulus and Pinus radiata into native eucalypt forests in Western Australia. Ecol Manag. 2018;424:246-58.

45. Tererai F, Gaertner M, Jacobs SM, Richardson DM. Eucalyptus invasions in riparian forests: effects on native vegetation community diversity, stand structure and composition. Ecol Manag. 2013;297:84-93.

46. Richardson DM, Macdonald IAW, Forsyth GG. Reductions in plant species richness under stands of alien trees and shrubs in the fynbos biome. South Afr J. 1989;149:1-8.

47. Schoch CL, Seifert KA, Huhndorf S, Robert V, Spouge JL, Levesque CA, et al. Nuclear ribosomal internal transcribed spacer (ITS) region as a universal DNA barcode marker for Fungi. Proc Natl Acad Sci. 2012;109:6241-6.

48. Abarenkov K, Nilsson RH, Larsson KH, Alexander IJ, Eberhardt U, Erland S, et al. The UNITE database for molecular identification of fungi-recent updates and future perspectives. N. Phytol. 2010;186:281-5.

49. Kõljalg U, Nilsson RH, Abarenkov K, Tedersoo L, Taylor AFS, Bahram M. Towards a unified paradigm for sequence-based identification of fungi. Mol Ecol. 2013;22:5271-7.

50. Altschul SF, Gish W, Miller W, Myers EW, Lipman DJ. Basic local alignment search tool. J Mol Biol. 1990;215:403-10.

51. Tedersoo L, May TW, Smith ME. Ectomycorrhizal lifestyle in fungi: global diversity, distribution, and evolution of phylogenetic lineages. Mycorrhiza. 2010;20:217-63.

52. Tedersoo L, Smith ME. Ectomycorrhizal fungal lineages: detection of four new groups and notes on consistent recognition of ectomycorrhizal taxa in high-throughput sequencing studies. In: Tedersoo L (ed.). Biogeography of Mycorrhizal Symbiosis. Springer International Publishing AG; Cham, Switzerland, 2017. pp 125-42.

53. Větrovský T, Kohout P, Kopecký M, Machač A, Man M, Bahnmann $\mathrm{BD}$, et al. A meta-analysis of global fungal distribution reveals climate-driven patterns. Nat Commun. 2019;10:1-9.

54. Vlk L, Tedersoo L, Antl T, Větrovský T, Abarenkov K, Pergl J, et al. Early successional ectomycorrhizal fungi are more likely to naturalize outside their native range than other ectomycorrhizal fungi. New Phytol. 2020.

55. Morrone JJ. Biogeographical regionalisation of the world: a reappraisal. Aust Syst Bot. 2015;28:81-90.

56. Oksanen J, Blanchet FG, Kindt R, Legendre P, Minchin PR, O'Hara RB, et al. Vegan: community ecology package. R package version 2.0-10. 2012.

57. Goslee SC, Urban DL. The ecodist package for dissimilaritybased analysis of ecological data. J Stat Softw. 2007;22:1-19.

58. Anderson MJ, Crist TO, Chase JM, Vellend M, Inouye BD, Freestone AL, et al. Navigating the multiple meanings of $\beta$ diversity: a roadmap for the practicing ecologist. Ecol Lett. 2011;14:19-28.

59. Crawley MJ. The R Book. Chichester: Wiley Publishing; 2007.

60. Řehák J, Řeháková B. Analýza kategorizovaných dat v sociologii [Analysis of categorical data in sociology]. Prague: Academia; 1986. 
61. Vinogradova Y, Pergl J, Essl F, Hejda M, van Kleunen M, Pyšek P. Invasive alien plants of Russia: insights from regional inventories. Biol Invasions. 2018;20:1931-43.

62. R Development Core Team. R: A language and environment for statistical computing. Vienna, Austria. Vienna, Austria: R Foundation for Statistical Computing; 2019.

63. Moyano J, Rodriguez-Cabal MA, Nuñez MA. Highly invasive tree species are more dependent on mutualisms. Ecology. 2020;101:e02997.

64. Richardson DM, Rejmánek M. Trees and shrubs as invasive alien species - a global review. Divers Distrib. 2011;17:788-809.

65. Alpert $P$. The advantages and disadvantages of being introduced. Biol Invasions. 2006;8:1523-34.

66. Catford JA, Jansson R, Nilsson C. Reducing redundancy in invasion ecology by integrating hypotheses into a single theoretical framework. Divers Distrib. 2009;15:22-40.

67. Molina R, Trappe JM. Biology of the ectomycorrhizal genus Rhizopogon I: host associations, host-specificity and pure culture syntheses. N. Phytol. 1994;126:653-75.

68. Bruns TD, Bidartondo MI, Taylor DL. Host specificity in ectomycorrhizal communities: What do the exceptions tell us? Integr Comp Biol. 2002;42:352-9.

69. Nguyen NH, Vellinga EC, Bruns TD, Kennedy PG. Phylogenetic assessment of global Suillus ITS sequences supports morphologically defined species and reveals synonymous and undescribed taxa. Mycologia. 2016;108:1216-28.

70. Malajczuk N, Molina R, Trappe JM. Ectomycorrhiza formation in Eucalyptus. I. Pure culture synthesis, host specificity and mycorrhizal compatibility with Pinus radiata. N. Phytol. 1982;91:467-82.

71. Mortenson SG, Mack RN. The fate of alien conifers in long-term plantings in the USA. Divers Distrib. 2006;12:456-66.

72. Reichard SH. Assessing the potential of invasiveness in woody plants introduced in North America. Seattle: University of Washington; 1994.

73. Hynson NA, Merckx VSFT, Perry BA, Treseder KK. Identities and distributions of the co-invading ectomycorrhizal fungal symbionts of exotic pines in the Hawaiian Islands. Biol Invasions. 2013;15:2373-85.

74. Hawley GL, Taylor AFS, Dames JF. Ectomycorrhizas in association with Pinus patula in Sabie, South Africa. S Afr J Sci. 2008;104:273-83.

75. Nuñez MA, Hayward J, Horton TR, Amico GC, Dimarco $\mathrm{RD}$, Barrios-Garcia MN, et al. Exotic mammals disperse exotic fungi that promote invasion by exotic trees. PLoS One. 2013;8:1-6.

76. Hayward J, Horton TR, Nuñez MA. Ectomycorrhizal fungal communities coinvading with Pinaceae host plants in Argentina: Gringos bajo el bosque. N. Phytol. 2015;208:497-506.

77. Tedersoo L, Bahram M, Jairus T, Bechem E, Chinoya S, Mpumba $\mathrm{R}$, et al. Spatial structure and the effects of host and soil environments on communities of ectomycorrhizal fungi in wooded savannas and rain forests of Continental Africa and Madagascar. Mol Ecol. 2011;20:3071-80.

78. Walbert K, Ramsfield TD, Ridgway HJ, Jones EE. Ectomycorrhizal species associated with Pinus radiata in New Zealand including novel associations determined by molecular analysis. Mycorrhiza. 2010;20:209-15.

79. Murat C, Díez J, Luis P, Delaruelle C, Dupré C, Chevalier G, et al. Polymorphism at the ribosomal DNA ITS and its relation to postglacial re-colonization routes of the Perigord truffle Tuber melanosporum. N. Phytol. 2004;164:401-11.

80. Põlme S, Bahram M, Yamanaka T, Nara K, Dai YC, Grebenc T, et al. Biogeography of ectomycorrhizal fungi associated with alders (Alnus spp.) in relation to biotic and abiotic variables at the global scale. N. Phytol. 2013;198:1239-49.

81. Setaro SD, Kron K. Neotropical and north american vaccinioideae (ericaceae) share their mycorrhizal sebacinales-an indication for concerted migration? PLoS Curr. 2011;3:RRN1227.

82. Kohout $\mathrm{P}$, Sýkorová Z, Bahram M, Hadincová V, Albrechtová J, Tedersoo L, et al. Ericaceous dwarf shrubs affect ectomycorrhizal fungal community of the invasive Pinus strobus and native Pinus sylvestris in a pot experiment. Mycorrhiza. 2011;21:403-12.

83. Pietras M, Kolanowska M. Predicted potential occurrence of the North American false truffle Rhizopogon salebrosus in Europe. Fungal Ecol. 2019;39:225-30.

84. Koske RE, Gemma JN, Flynn T. Mycorrhizae in hawaiian angiosperms: a survey with implications for the origin of the native flora. Am J Bot. 1992;79:843-52.

85. Lososová Z, de Bello F, Chytrý M, Kühn I, Pyšek P, Sádlo J, et al. Alien plants invade more phylogenetically clustered community types and cause even stronger clustering. Glob Ecol Biogeogr. 2015;24:786-94.

86. Divíšek J, Chytrý M, Beckage B, Gotelli NJ, Lososová Z, Pyšek $\mathrm{P}$, et al. Similarity of introduced plant species to native ones facilitates naturalization, but differences enhance invasion success. Nat Commun. 2018;9:1-10.

87. Elton CS. The ecology of invasions by animals and plants. London: Methuen; 1958.

88. Obase K, Douhan GW, Matsuda Y, Smith ME. Progress and challenges in understanding the biology, diversity, and biogeography of Cenococcum geophilum. Biogeography of Mycorrhizal Symbiosis. Springer International Publishing; Cham, Switzerland, 2017. pp 299-317.

89. Chapela IH, Osher LJ, Horton TR, Henn MR. Ectomycorrhizal fungi introduced with exotic pine plantations induce soil carbon depletion. Soil Biol Biochem. 2001;33:1733-40.

90. Read DJ, Perez-Moreno J. Mycorrhizas and nutrient cycling in ecosystems - a journey towards relevance? N. Phytol. 2003;157:475-92.

91. Clemmensen KE, Finlay RD, Dahlberg A, Stenlid J, Wardle DA, Lindahl BD. Carbon sequestration is related to mycorrhizal fungal community shifts during long-term succession in boreal forests. $\mathrm{N}$. Phytol. 2014;205:1525-36.

92. Jairus T, Mpumba R, Chinoya S, Tedersoo L. Invasion potential and host shifts of Australian and African ectomycorrhizal fungi in mixed eucalypt plantations. N. Phytol. 2011;192:179-87.

93. Buyck B. The edible mushrooms of Madagascar: an evolving enigma. Econ Bot. 2008;62:509-20.

94. Pennington HG, Bidartondo MI, Barsoum N. A few exotic mycorrhizal fungi dominate eucalypts planted in England. Fungal Ecol. 2011;4:299-302.

95. Kjøller R. Disproportionate abundance between ectomycorrhizal root tips and their associated mycelia. FEMS Microbiol Ecol. 2006;58:214-24.

96. Johnson NC, Wilson GWT, Bowker MA, Wilson JA, Miller RM. Resource limitation is a driver of local adaptation in mycorrhizal symbioses. Proc Natl Acad Sci. 2010;107:2093-8.

97. Bashir H, Khalid AN. Morpho-anatomical and molecular characterisation of ectomycorrhizae associated with Eucalyptus species growing in different areas of the Punjab Province, Pakistan. Aust J Bot. 2014;62:689-97.

98. Tedersoo L, Bahram M, Põlme S, Kõljalg U, Yorou NS, Wijesundera R, et al. Global diversity and geography of soil fungi. Science. 2014;346:1256688.

99. Stevens PF. Angiosperm Phylogeny Website. Version 14, July 2017 [and more or less continuously updated since]. http://www. mobot.org/MOBOT/research/APweb/. 